\title{
Medios de comunicación en la protección de la infancia: una lección que aprender
}

\author{
Diana Elisa González Calderón y \\ María de las Mercedes Portilla Luja
}

\section{Resumen}

Los medios de comunicación son un espacio de aprendizaje alterno que influye en la conformación de roles, modos y costumbres. A la luz de la Ley General de Derechos de niñas, niños y adolescentes en México, se establece un sistema de protección integral que contempla la suma de acciones desde diversos frentes; los medios de comunicación tienen un papel primordial. El objetivo de este artículo es reflexionar sobre la construcción de las representaciones mediáticas, como parte de un sistema de protección a los derechos de infancia. Para el análisis se establecieron criterios basados en los cuatro ejes rectores de la Convención de los Derechos del niño. Se hizo evidente la necesidad de fortalecer un nuevo escenario donde las representaciones de los medios coadyuven a la protección de derechos de infancia que marca la ley.

Palabras clave: derechos del niño, protección, medios de comunicación, representaciones mediáticas.

\section{THE ROLE OF MEDIA IN CHILDREN PROTECTION: A LESSON TO BE LEARNED}

\begin{abstract}
Media is an alternate learning space that influences the conformation of roles, manners and customs. In light of the General Law for the Rights of girls, boys and teenagers in Mexico, a system of integral protection that contemplates actions from varied fronts was established, in which media has an essential role. The goal of this paper is to consider the construction of media representations as a part of a system designed to protect children's rights. A criteria was established based on the four guiding principles of the Children's Rights Convention to support the analysis. The need to consolidate a scenario where representation in media supports the children's rights as stated by the law was made evident.
\end{abstract}

Keywords: children's rights, protection, media, media representations.

DOI: http://doi.org/10.22201/codeic.16076079e.2019.v20n5.a6 
"Medios de comunicación en la protección de la infancia: una lección que aprender"

\section{Diana Elisa González Calderón}

Doctora en Contenidos de Comunicación en la Era Digital por la Universidad Autónoma de Barcelona, España. Profesora-Investigadora de Tiempo Completo con Perfil PRODEP en la Facultad de Arquitectura y Diseño de la Universidad Autónoma del Estado de México (UAEMex). Sus líneas de investigación son la imagen y los medios de comunicación desde los estudios de género y el enfoque de derechos de infancia.

\section{María de las Mercedes Portilla Luja}

invposgradofad@gmail.com orcid.org/0000-0001-9318-9102

redalyc.org/autor.oa?id $=2733$

Doctora en Humanidades. Filosofía Contemporánea por la UAEMex. Profesora-Investigadora de Tiempo Completo con Perfil PRODEP en la Facultad de Arquitectura y Diseño de la UAEMex. Sus líneas de investigación son el diseño desde la diversidad cultural para el desarrollo social, así como el tema "Cultura de paz y cultura de la violencia: construcción discursiva desde la imagen".

Integrante del Cuerpo Académico Consolidado (SEP) UAEM-173 Diseño y Desarrollo Social, de las redes nacionales de investigación de Diseño y Desarrollo Social y de la Red de Vulnerabilidad e Inclusión.

\section{Introducción}

Toda experiencia tiene impacto en la conformación del ser humano y las experiencias de la infancia tienen repercusiones positivas o negativas en la construcción de la adultez. Gran cantidad de niñas, niños y adolescentes es violentada todos los días ante ignorancia u omisión de políticas públicas que protejan sus derechos. Cifras oficiales señalan un gran rezago en educación, nutrición, salud, vivienda, así como altos niveles de violencia, embarazo adolescente y desprotección para la población indígena, según reporta el diagnóstico de niñez del Sistema Nacional de Protección Integral de Niñas, Niños y Adolescentes (SIPINNA, s/f).

La Ley General de los Derechos de Niñas, Niños y Adolescentes, que se publica en 2014, establece un nuevo paradigma de relación con la infancia. De ser considerados sujetos que requieren la protección de los adultos, se determina que son sujetos con derechos, mismos que deben ser protegidos. Esto fortalece un nuevo escenario de relación pues la ciudadanía se construye desde edad temprana. 
Fotografía 1.

Elaboración propia.

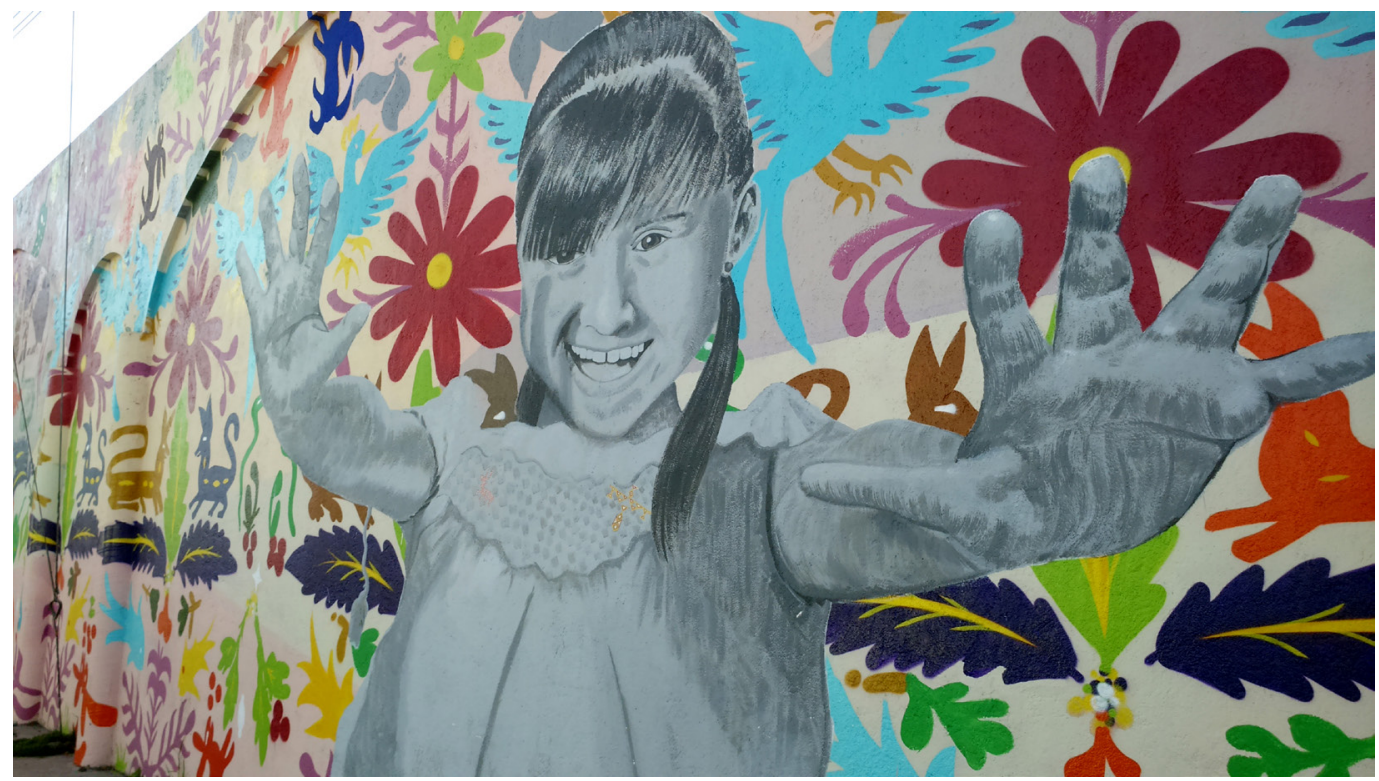

Derivado de esta ley, surge un Sistema Nacional de Protección Integral de los Derechos de Niñas, Niños y Adolescentes que es responsable de articular y coordinar las políticas públicas dirigidas a la infancia desde los distintos niveles de gobierno, así como los diversos actores institucionales con el afán de generar acciones responsables en este sector de la población. El enfoque de infancia atiende al compromiso prioritario que plantea la convención:

[...] los países asumieron el compromiso de cumplir cabalmente con sus disposiciones, adecuar sus leyes a estos principios, colocar a la infancia en el centro de sus agendas a través del desarrollo de políticas públicas y a destinar el mayor número de recursos posibles para la niñez y la adolescencia (UNICEF, S/f).

Uno de los objetivos del Programa Nacional de Protección de Niñas, Niños y Adolescentes 2016-2018 es el referente a la participación y cambio cultural, en el que los contenidos en medios de comunicación se destacan como una estrategia enfocada a su cumplimiento. Así, el valor de los mensajes que se generan desde los medios es de influencia e impacto, y transmiten valores sustanciales para lograr los objetivos del sistema de protección.

La cantidad de información que recibe un niño desde los medios favorece la imposición de mensajes, que son cruciales para generar una acción en ellos (Huertas, 1988). Fue Giovanni Sartori (1998) quien señalara el riesgo en la infancia sobre la exposición constante a un medio como la televisión, ya que empobrece la mente. Con ello detonó la incógnita sobre el tipo de ser humano que se forma desde estos consumos y prácticas donde lo visible supera lo inteligible. De igual manera, García Canclini (2008) reflexiona en torno a las audiencias, las pantallas y retoma así los planteamientos de Castells (2007) respecto a la observación de la tecnosociabilidad, que implica no sólo hablar de herramientas sino de contextos - condiciones ambientales que hacen nuevas maneras de ser, nuevas 
cadenas de valores y nuevas sensibilidades sobre el tiempo, el espacio y los acontecimientos culturales- (Castells, 2007: 226).

Hay una serie de elementos sociales que refuerzan lo que dicen los medios, como la escuela, los amigos y la familia (Orozco, 1997). Por lo anterior, es sustancial promover la alfabetización en la gramática de los medios (Galindo, 1988), que implica actualmente un proceso de desarrollo que se caracterice "por la apropiación significativa de las competencias intelectuales, sociales y éticas necesarias para interactuar con la información y recrearla de un modo crítico y emancipador [...] es un derecho y una necesidad de todos y de cada uno de los ciudadanos de la sociedad informacional" (Area y Pessoa, 2012: 15).

Ante este contexto, el presente documento plantea una serie de reflexiones con respecto al uso de las representaciones mediáticas y el impacto de los consumos culturales como formativos en la infancia, lo que, a razón del sistema de protección que plantea la Ley General de los Derechos de Niñas, Niños y Adolescentes (2014), debería ser un mecanismo consciente de su responsabilidad y un engrane más del sistema de defensa de derechos de niñas, niños y adolescentes.

Se parte de un corpus basado en la teoría de la imagen y la comunicación (Barthes, 1986), que considera que atrás de toda enunciación hay un receptor que da sentido al estímulo enviado, que lo que es signo comunica (ya sea visual o auditivo) con una ideología de trasfondo. Además, toma como referente la Convención de los Derechos del Niño y, de manera contextual, la Ley General de Derechos de Niñas, Niños y Adolescentes en México.

Fotografía 2. Elaboración propia.

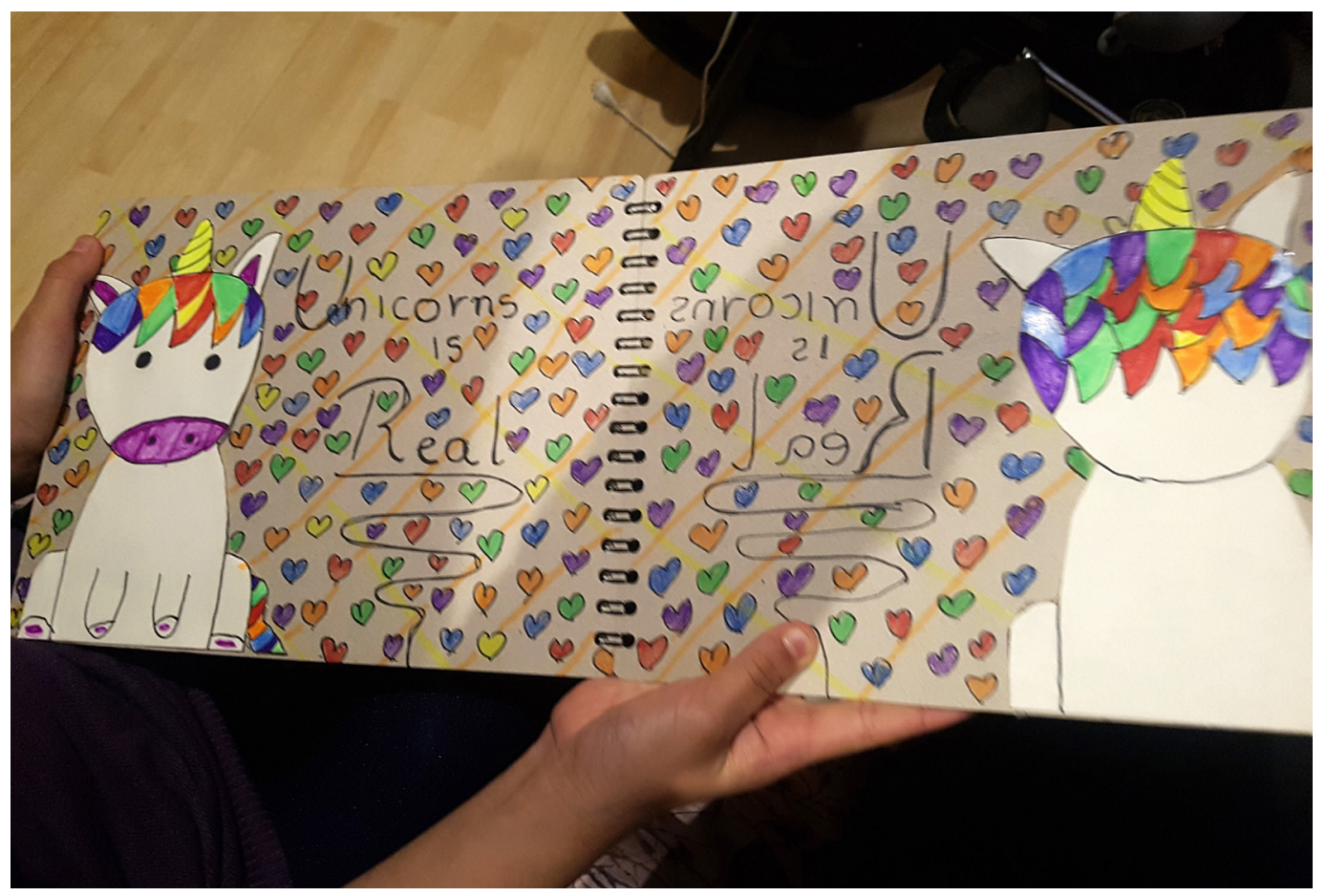


El corpus de análisis respondió a los siguientes criterios de selección:

- Ser representaciones dirigidas a niñas, niños y adolescentes.

- Ser representaciones en medios masivos y de gran alcance, por la influencia y acceso a grandes públicos.

- Ser representaciones de actualidad por la posibilidad de identificación.

Desde estos criterios se identificó cierta publicidad de juguetes y algunos productos de tipo televisivo y cinematográfico, por lo que se decidió retomar los más representativos, que permitieran destacar los objetivos del documento y de la necesaria conexión con el sistema de protección que marca la ley, para distinguir con mayor claridad aportes, así como la ausencia del enfoque de derechos de las infancias.

Se trata de una investigación de contenido de tipo cualitativo, con la intención de descubrir y comprender lo que se genera desde el discurso de la imagen a través de sus elementos significativos. El análisis, fue dividido en dos momentos:

1. Se inició con la revisión del producto mediático desde los cuatro ejes rectores de la Convención de los Derechos del niño, al ser quienes sustentan la Ley General y establecen los requerimientos de protección de derechos de infancia.

Los ejes rectores de la convención son:

- La no discriminación.

- El interés superior del niño.

- El derecho a la vida, la supervivencia y el desarrollo.

- La participación.

2. En un segundo momento, se analizó el producto desde dos niveles de sentido: lo denotativo y lo connotativo, con la intención de identificar las estructuras simbólicas que marcan una ideología desde el discurso de emisión.

\section{Desarrollo}

Reflexionar desde los ejes de la convención favoreció la discusión sobre los requerimientos en esta etapa de vida y la importancia de los productos culturales de tipo mediático que se dirigen a la infancia como escenarios de influencia formativa y de educación alterna.

Entre los hallazgos, se identificó la mirada adultocéntrica de trasfondo, lo que hace evidente la visión jerárquica y de poder entre grupos de edad (UNICEF, 2013). Niñas, niños y adolescentes no dan voz a sus deseos y acciones. Se detectó un continuo "deber ser" bajo la lógica del adulto, lo que se percibe 
en un tono didáctico, en permanente moraleja. No sólo se trata de aparecer a cuadro y ser representado para creer que se fomenta la participación infantil. Es brindar la oportunidad de enunciarse desde sus propias ideas y razonamientos. Históricamente, la infancia ha sido ubicada en un estrato inferior al de los adultos, situación que quitó voz y delegó a niñas, niños y adolescentes a un sitio que sólo podía romperse con la anuencia del padre. Curiosamente, no siempre de la madre, por lo que también fue patriarcal. De aquí que la discriminación no sólo se ha llevado a cabo de manera vertical entre padres, madres, hijos e hijas, sino también de manera horizontal en las relaciones entre hombres y mujeres desde el interior de la pareja o entre hermanos y hermanas.

La no discriminación señala que todas las niñas y niños deben ser considerados por igual; ésta debería ser una constante plasmada desde el discurso de los medios. Hay una naturalización de estereotipos que siguen posicionando roles pasivos y activos según el género, así como del uso de cierta estética que fomenta el trato jerárquico según el tono de piel, sexo o religión.

La discriminación se hace evidente a través de elementos sígnicos visuales y lingüísticos en el escenario de la representación. Hay una ausencia de diversidad y variedad de estratos sociales, circunstancia o condición. Esto da paso a una generalización estética de niñas, niños y adolescentes. Mostrar la variedad social y de edad en los medios con una visión plural es un elemento que apoyaría la inclusión y normalización de la presencia de grupos ausentes en el escenario mediático, como el caso de personas con alguna discapacidad o de cierto grupo étnico.

Fotografía 3.

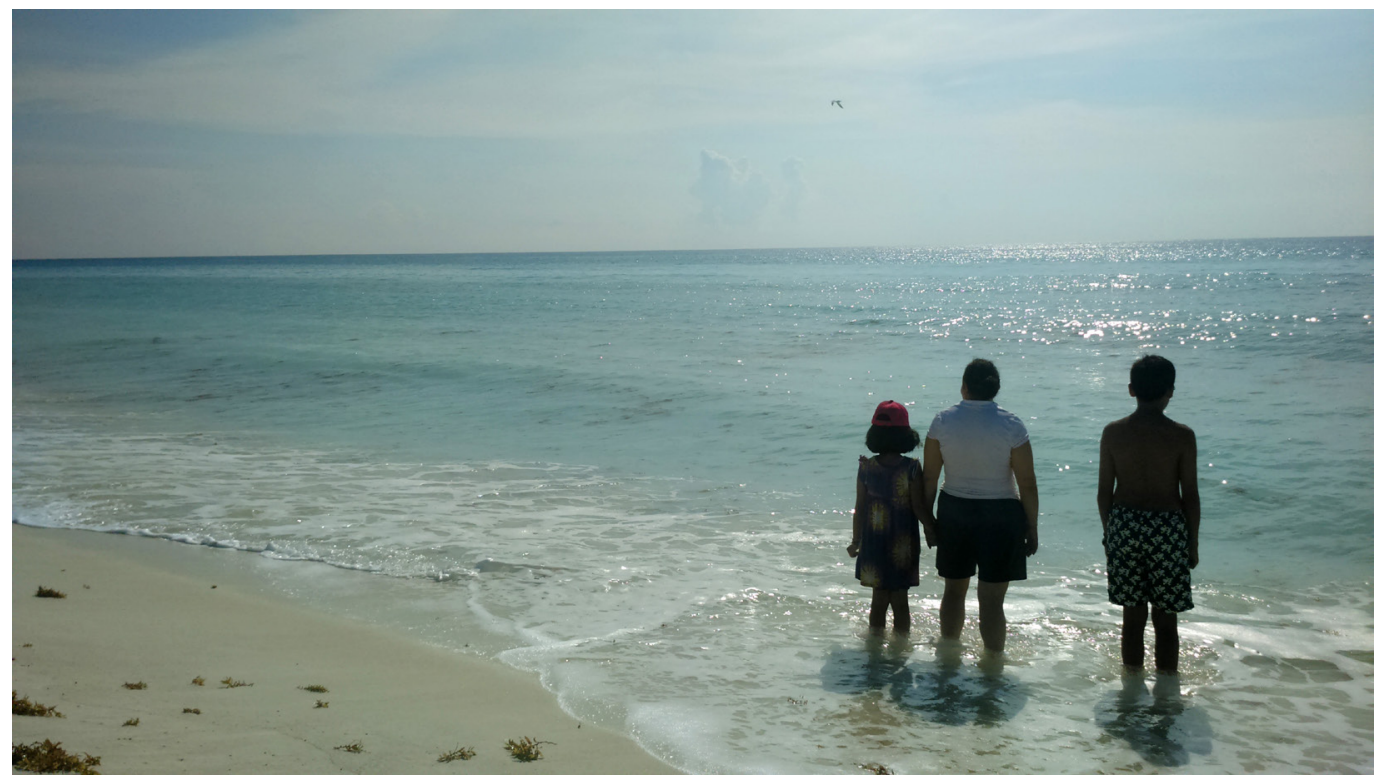

Desde el derecho a la vida, la supervivencia y el desarrollo, se identifica como un riesgo la sexualización precoz de las niñas. La exagerada carga de elementos no aptos para su edad, en cuanto a tacones, maquillaje y ropa del estilo de jóvenes 
y adultos, pone en evidencia una mala comprensión de esta etapa de vida. Lo anterior se podría traducir, en muchos casos, en una posible explicación, más no justificación, a problemáticas como violencia sexual infantil o matrimonio en la infancia.

Las representaciones siguen en permanente apego al estereotipo, lo cual es "una opinión o un prejuicio generalizado acerca de atributos o características que hombres y mujeres poseen o deberían poseer o de las funciones sociales que ambos desempeñan o deberían desempeñar"(Oficina del Alto Comisionado para los Derechos Humanos [OACDH], s/f). De esta manera, asignar atributos desde la generalización impulsa desventajas entre hombres y mujeres al limitar las posibilidades de desarrollo por haber una norma asimétrica de valoración. De trasfondo se enseña una forma de relación con el otro/otra y se conforman imaginarios de mujer/hombre.

En una gran cantidad de casos, a las niñas se les sigue encasillando en las labores domésticas o privadas y al hombre en el ámbito de lo público y la acción. Las niñas están vinculadas a lo "decorativo" y los niños generan movimiento o resolución a los hechos. La construcción de la idea de "verdad", que se genera desde la imagen de los medios, manda en una gran cantidad de casos un mensaje limitativo a las niñas: de seres incapaces, que deben ser protegidos y que requieren una valoración masculina para generar autoaceptación. Encasillar a las niñas como buenas para ciertas actividades y malas para otras es una consigna histórica que requiere de estrategias deconstructivas, como fue señalado en las décadas de los sesentas y setentas con el movimiento de las mujeres.

Fotografía 4.

Elaboración propia.

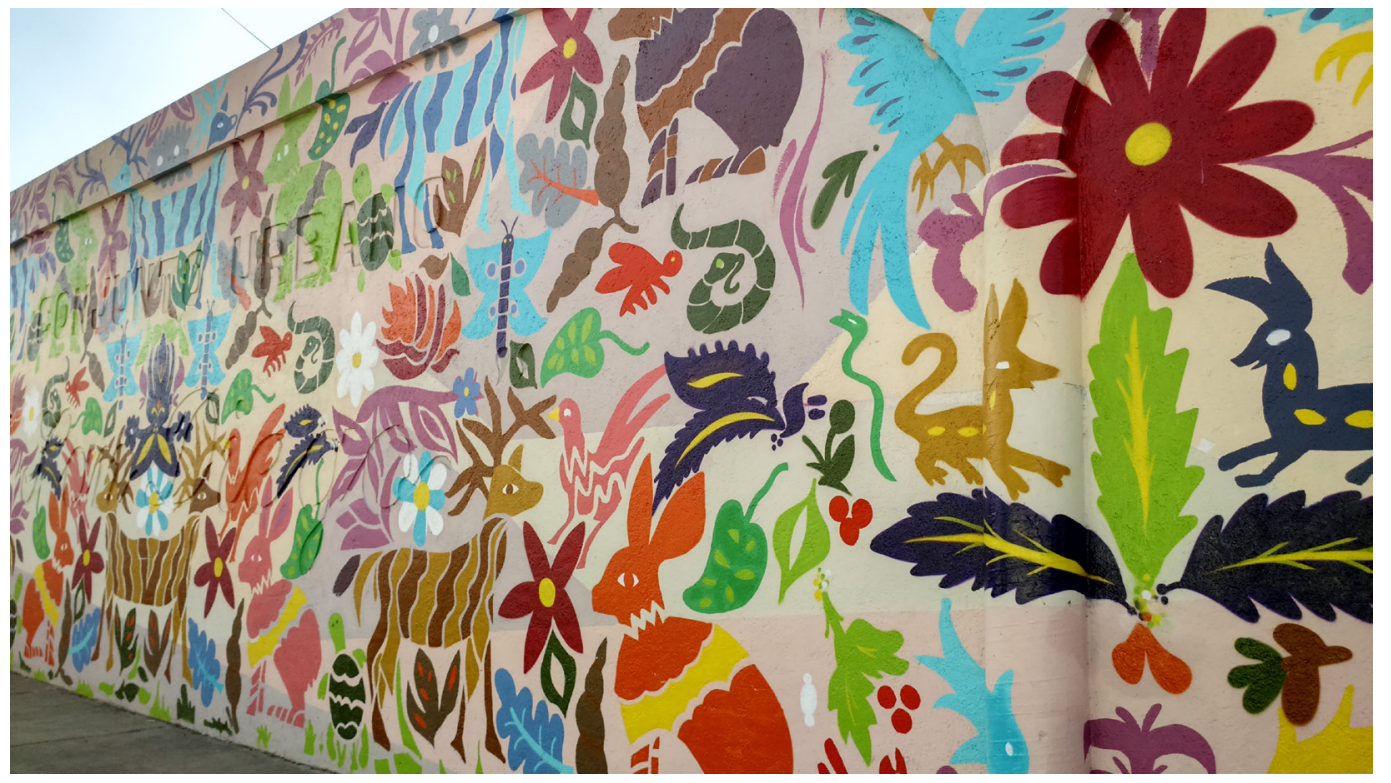


"Medios de comunicación en la protección de la infancia: una lección que aprender"

En cuanto al derecho a la vida, la supervivencia y el desarrollo "todos los niños y niñas tienen derecho a vivir y a tener un desarrollo adecuado" (UNICEF, $\mathrm{s} / \mathrm{f}$ ), lo que conlleva desde los medios a la promoción de la salud sexual, mental, nutricional, el acceso a la educación, así como al cuidado de las imágenes con contenido que promueva un sano crecimiento y promoción de valores, para limitar aquellos no aptos a su edad, que distorsionan la comprensión del enfoque adecuado. En el caso de la violencia, se trata de reprobar su naturalización desde edad temprana. Hacer visible, desde la imagen representada, la violencia de tipo simbólica y su consecuente rechazo como medida didáctica y preventiva.

Cualquier decisión que afecte al niño, niña o adolescente debe ser pensada desde el impacto que tendrá en su vida, para tomar las acciones que convengan a su desarrollo, según la UNICEF (S/f). Pensar en el interés superior de la niñez apunta a la consideración de lo que satisface sus necesidades básicas, así como sus deseos y opiniones; la conveniencia de un entorno adecuado y libre de violencia, su edad y madurez, lo que preserve su identidad, la garantía de igualdad y no discriminación, así como estabilidad (Barredo, 2016).

El lugar prioritario que la Ley General de Derechos de Niñas, Niños y Adolescentes pide, a través del sistema de protección integral, convoca, entonces, a visibilizar que son las infancias (en plural) las que deberían tener cabida en el escenario de los medios, lo que apunta a hacer visible la variedad y circunstancia.

Desde la imagen de los medios, es posible identificar "un elenco de miradas, organizado, en el que conviven diferentes visiones (histórica, pedagógica, psicológica y social, como sujeto de derechos y políticas sociales, etc.)" (SánchezValverde, 2016: 55).

Es un reto romper estereotipos y abrir el escenario de lo visible a seres no limitados por el género, por su condición, por su edad. Los juguetes en sí mismos y sus anuncios comerciales, así como los personajes de gran cantidad de programas televisivos y cinematográficos, tendrían la gran oportunidad de impulsar nuevas formas de pensar y de pensarse, así como de relacionarse con otros.

La participación infantil es estrategia de construcción de ciudadanía y promoción de responsabilidades en las decisiones que conforman a un ser humano. "Niñas y niños tienen derecho a participar para construir acuerdos y reglas que les ofrezcan bienestar y tranquilidad" (Pisoni, 2017: 13). Participar es reconocer la voz y las ideas del otro y otra, lo que abre a un escenario con riqueza de propuestas desde edad temprana. Por ello, es importante definir algunas líneas de acción estratégica que apoyen al sistema de protección desde la imagen de los medios:

- Es importante promover la participación infantil desde la producción de contenidos como una oportunidad de dar voz y visibilizar las ideas, deseos y necesidades de quienes están en esta etapa de vida. Pueden 
"Medios de comunicación en la protección de la infancia: una lección que aprender"

ser guiados por especialistas adultos, que sepan respetar y dar cauce a estas experiencias.

- Es necesario promover la creación de observatorios de medios que faciliten la intervención ante acciones que vulneren los derechos de niñas, niños y adolescentes. Sólo así será posible desnaturalizar la violencia simbólica que deviene de una omisión probable, o bien, de todo acto declarado contra los derechos de infancia.

- Es imprescindible entender que la educación es un agente de cambio. La educación en valores desde la infancia y visible en sus consumos culturales, aunado a la práctica cercana y permanente, será el mejor aprendizaje para niñas y niños.

- Es necesario formar receptores responsables de sus consumos culturales desde la infancia. Dotar a niñas, niños y adolescentes de los mecanismos críticos acordes a su edad, para favorecer el consumo responsable, en cuanto a cantidad de tiempo frente a los medios, así como en calidad de lo observado desde una función didáctica. De esta manera, es indispensable promover ejercicios de alfabetización visual y mediática desde temprana edad.

\section{Conclusiones}

México requiere trabajar enfáticamente con niñas, niños y adolescentes la educación en los medios, generar cierta comprensión de la experiencia mediática, que de por resultado una mirada crítica y reflexiva en cuanto a estética, patrones de conducta, así como de consumos culturales específicos, y que aminore la educación informal que se genera desde estos escenarios con resultados que no son siempre positivos en el desarrollo de dichos individuos.

Fortalecer el conocimiento de derechos de infancia desde las instituciones, políticas públicas, programas y actores abonaría al necesario cambio social. Impulsar desde los medios un nuevo concepto de niña, niño y adolescente, sin prejuicio de raza, género y condición podría ser la semilla a una nueva sociedad más consciente de su pluralidad.

Considerar la educación en valores desde la infancia es pilar de desarrollo del ser humano. Hace falta un cambio y los medios son un escenario estratégico de intervención, así como de aprendizaje a favor de una sociedad más incluyente, más solidaria y, por lo tanto, respetuosa de los derechos humanos. Es aquí donde toma prioridad un sistema de protección que tenga claridad en sus protocolos preventivos y de atención a la vulneración de derechos de infancia.

Es indispensable señalar la urgencia de construir un sistema de garantía de derechos que convoque y promueva la participación social desde edad temprana. Que reconozca la importancia de incidir en la primera infancia, así como la experiencia de vida distinta que supone el haber nacido niño o niña. Que conciba a la adolescencia como grupo vulnerable y apoye la necesidad 
"Medios de comunicación en la protección de la infancia: una lección que aprender"

de desagregarlo del grupo de niñez por las consideraciones que implica cada etapa de vida. Por ello se requiere la articulación de instituciones, programas y actores estratégicos, en donde los medios entiendan su papel fundamental en el cambio cultural, así como de cambio de paradigmas. La niñez y adolescencia son el presente y el cimiento de un mejor futuro, los medios tienen la gran responsabilidad de abonar su parte a un sistema que proteja sus derechos.

\section{Referencias}

* Area, M. y Pessoa, T. (2012). De lo sólido a lo líquido: las nuevas alfabetizaciones mediáticas ante los cambios culturales de la Web 2.0. Comunicar, 38,13-20. DOI: https://doi.org/10.3916/C38-2011-02-01.

* Barthes, R. (1986). Lo obvio y lo obtuso: imágenes, gestos, voces. Barcelona: Paidós.

* Barredo, B. (2016). Participación efectiva y ejercicio responsable de los derechos del menor como ciudadano. Revista de intervención psicosocioeducativa en la desadaptación social, 9, 11-20. Recuperado de: http://ipseds.ulpgc.es/IPSE-ds Vol 9 2016/IPSE-ds-9.pdf.

- Castells, M., Fernández-Ardèvol, M., Linchuan Qiu, J. y Sey, A. (2007). Comunicación móvil y sociedad, una perspectiva global. México: Editorial Ariel/Fundación Telefónica.

* Galindo, E. (1988). Hacia una teoría de la imagen. Perfiles educativos, 41-42, 77-84. Recuperado de: http://www.iisue.unam.mx/perfiles/articulo/1988-41-42-haciauna-teoria-de-la-imagen.pdf.

* García Canclini, N. (2008). Libros, pantallas y audiencias: ¿qué está cambiando? Comunicar, 30(XV), 27-32. DOI: https:/doi.org/10.3916/c30-2008-01-004.

* Huertas, M. (1998). La televisión: el padre ficticio. Pharos, 5(2), 87-97. Recuperado de: http://www.redalyc.org/pdf/208/20805210.pdf.

* Oficina del Alto Comisionado para los Derechos Humanos (OACDH). (S/f). LOS estereotipos de género y su utilización. Recuperado de: http://www.ohchr.org/SP/ Issues/Women/WRGS/Pages/GenderStereotypes.aspx.

- Orozco, G. (1997). Medios, audiencias y mediaciones. Comunicar, 8, 25-30. Recuperado de: http://www.redalyc.org/pdf/158/15800806.pdf.

* Pisoni, M. (2017). Guía de participación para niñas y niños. México: INE-SIPINNAUNICEF. Recuperado de: https://www.ine.mx/wp-content/uploads/2019/04/GUIA ninas y ninos.pdf.

* Sánchez-Valverde, C. (2016) El interés superior del niño y de la niña. El debate ideológico a través de las denominaciones: ¿niño/niña? o ¿menor? Revista de intervención psicosocioeducativa en la desadaptación social, 9, 55-68. Recuperado de: http://ipseds.ulpgc.es/IPSE-ds Vol 9 2016/IPSE-ds-9.pdf. 
"Medios de comunicación en la protección de la infancia: una lección que aprender"

- Sartori, G. (1998). Homo Videns. La sociedad teledirigida. Madrid: Taurus.

* Sistema Nacional de Protección Integral de Niñas, Niños y Adolescentes (SIPINNA) (s/f). Infografía sobre diagnóstico de niñez. Recuperado de: https://impinforma.mx/ wp-content/uploads/2018/10/Infografia-Di\%C3\%A1gnostico-de-Ni\%C3\%B1ez. pdf.

* Sistema Nacional de Protección Integral de Niñas, Niños y Adolescentes (SIPINNA) (s/f). Ley General de los Derechos de las niñas, los niños y los adolescentes. Recuperado de: https://www.gob.mx/sipinna/articulos/ley-general-de-los-derechos-de-ninasninos-y-adolescentes-ya-la-conoces-107204?idiom=es.

- UNICEF (s.f.a). Derechos de los niños. Recuperado de: http://www.unicef.es/infancia/ derechos-del-nino.

- UNICEF (s.f.b). Derechos de la niñez. Recuperado de: http://www.unicef.org/mexico/ spanish/17054.htm.

- UNICEF (2013). Superando el adultocentrismo. Recuperado de: https://unicef.cl/web/ wp-content/uploads/2012/12/UNICEF-04-SuperandoelAdultocentrismo.pdf.

\section{Cómo citar este artículo}

* González Calderón, Diana Elisa y Portilla Luja, María de las Mercedes (2019). Medios de comunicación en la protección de la infancia: una lección que aprender. Revista Digital Universitaria (RDU). Vol. 20, núm. 5 septiembre-octubre. DOI: http:// doi.org/10.22201/codeic.16076079e.2019.v20n5.a6.

Recepción: 01/02/2018. Aprobación: 28/06/2019 